\title{
SCREENING EFFICIENCY ANALYSIS OF VIBROSIEVES WITH THE CIRCULAR VIBRATIONS
}

\author{
Jelena M. DJOKOVIĆ ${ }^{1,{ }^{*}}$, Dejan I. TANIKIĆ ${ }^{1}$, Ružica R. NIKOLIĆ², Saša M. \\ KALINOVIĆ ${ }^{1}$ \\ ${ }^{1}$ Technical Faculty in Bor, University of Belgrade, Serbia. \\ ${ }^{2}$ Faculty of Engineering, University of Kragujevac, Serbia; Research Centre, University of Žilina, \\ Slovakia. \\ corresponding author: ruzicarnikolic@yahoo.com
}

\section{Abstract}

The analysis of influence of factors that depend on construction characteristics of the vibrosieves with circular vibrations on screening efficiency is presented in this paper. The dependence of the screening efficiency on the aperture size, length and inclination of the screen, as well as on vibration amplitude, is considered. Based on obtained results, one can see that the screening efficiency increases with vibration amplitude and the screen length increase. Further, increases of the screen inclination and aperture size are causing an initial increase of the screening efficiency, which is later decreasing.
\end{abstract}

\section{Keywords:}

Screening efficiency; Vibrational sieves;

Circular vibration mode;

Screen length;

Screen inclination.

\section{Introduction}

Sieving is one of the oldest processes of separating raw materials or products and it is widely used in various branches of industry, as well as in research laboratories. It is based on geometrical comparison of shape and size of particles with a shape and size of the screen aperture. The screen is fixed to the frame of the sieve. The raw material, that is being sieved, is moving over the screen either due to its inclination or its movement.

Vibration sieves are the most common devices used to sieve various materials. There are several different types of vibration sieves. They have wide application in many engineering areas, like mining, metallurgy, construction engineering and agriculture. The vibration sieve consists of the frame, which is placed on the elastic supports, mechanism that induces vibrations, electro motor, screens and transmission mechanism, Fig. 1.

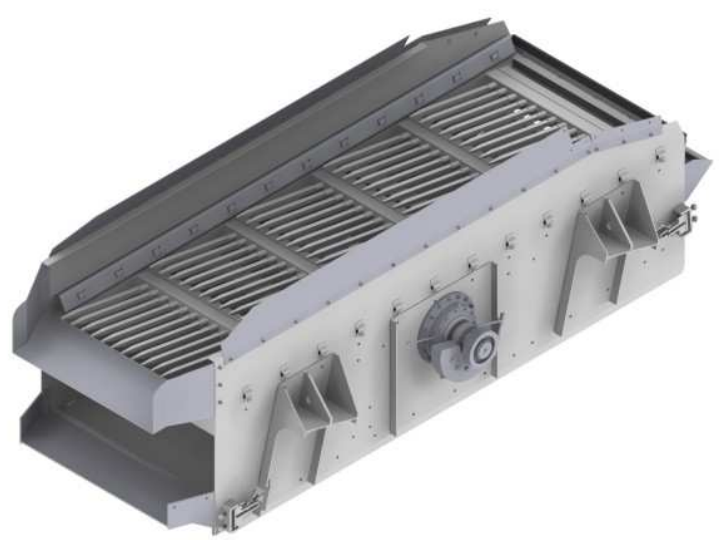

Fig. 1: Vibration sieve.

The way of the raw material motion over the screen influences, to a great extent, the capacity and screening efficiency of the vibration sieves. They are, according to the way of the frame movement, classified as vibration sieves with linear, circular and elliptical vibrations. The sieves can have one or several screens, which can be horizontal or inclined. 
The screening efficiency of vibrational sieves was a subject of research reported in numerous papers, like Li et al. (2003), Lu (2009), Wang and Tong (2011), Zhao et al. (2011) and Delaney et al. (2012). The qualitative relations between the screening efficiency and some sieving parameters were obtained in these papers, like the particle size, screen aperture size, vibration frequency and amplitude. The screening efficiency was also studied by Grozubinsky et al. (1998) and Chen and Tong (2010), which proposed the relation between the screening efficiency and those sieving parameters, as well as the angle of vibrations' direction, based on the probability theory and the Discrete Element Model (DEM) simulation. Their expressions gave the relation only between the individual sieving parameters and the screening efficiency. The DEM simulation results have to be further improved and tested for the specific material and boundary conditions. Jiao et al. (2007) have proposed the mathematical formula for relating the screening efficiency and the sieve aperture size, based on the statistical analysis of experimental data, but they did not take into account the influence of the screen's length. Despite the fact that there exist several formulae with which one can analyse the screening efficiency in terms of the various parameters, there is no generally accepted formula for predicting the screening efficiency based on the screening parameters, which depend on the constructive characteristics of the device. Introduction of the artificial intelligence might represent the good way for solving this problem, what was demonstrated in works by Umehara et al. (2006) and Ferentinos and Tsiligiridis (2007).

The screening efficiency and possibility can be influenced by several factors. All those factors can be categorized in three groups. The first group contains factors caused by the sieved material properties like moisture, granulometric content and shape of particles and presence of the clay materials. The factors that depend on the construction characteristics of the sieving device constitute the second group of parameters, where one assumes the shape and size of the screen's aperture, as well as its inclination and the sieve's vibrations number and amplitude. The factors of the third group of factors depend on characteristics of the sieving process, i.e. the feeding rate of the raw material and the thickness of the raw material's layer on the screen.

All the mentioned factors directly influence the probability of screening, which, on the other hand, directly affects the screening efficiency, as well as the capacity of the sieve for the certain screening effect.

The shape of the aperture affects the coarseness of the product and the screen's capacity. For the same characteristic dimension of the aperture (the diameter of the circular aperture, the side of the square $v$ and the width of the rectangular aperture) and the screening area, the largest capacity is obtained for the rectangular aperture, then for the square ones, while the least capacity have the circular aperture. The shape of the aperture also influences, to the certain extent, the ratio between the total area of the aperture and the total area of the screen. The larger the value of this ratio, the larger is the capacity of the sieving screen.

The influence of the second group of factors, i.e. factors that depend on the construction characteristics of the sieving device, on the screening efficiency of the vibration sieves with the circular vibration mode is considered in this paper.

\section{The problem formulation}

During the sieving of particles of various sizes, we differentiate between the particles that are smaller than the screen aperture, the so-called undersized particles and the particles that remain above the screen surface (i.e. that did not fall through the aperture and can also contain the undersize particles), which are called the overflow particles.

The term screening (sieving) efficiency implies the successfulness of sieving with respect to ideal sieving, which would result in complete separation of particles size classes, without presence of the undersize particles in the overflow product and particles larger than the screen slots in the undersize product. The sieving effect represents the ratio of the mass of the undersize particles in the under-sized product and the total quantity of the undersize particles in the input raw material (e.g. ore). In the other words, the screening efficiency is calculated as the ratio of the mass of undersize particles collected in the bins to the mass of feeding material finer than the screen aperture.

The scheme of sieving with parameters depending on the construction properties is presented in Fig. 2. 


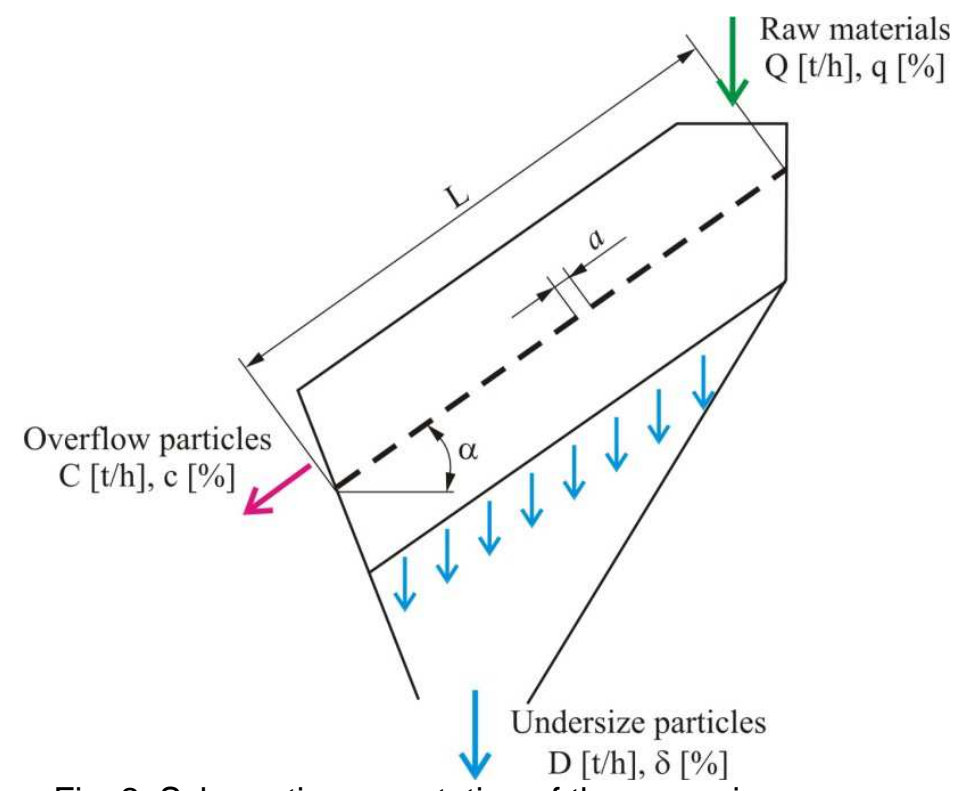

Fig. 2: Schematic presentation of the screening process.

Notation in Fig. 2 is the following: $a$ is the size of the aperture, $L$ is the screen's length and $\alpha$ is the screen's inclination angle. From Figure 2 one can see that $Q$ denotes the mass of the material being fed-in for screening, $C$ is the mass of the overflow particles and $D$ is the mass of the undersize particles. If the percentage of particles, whose size is smaller than the aperture, in the fed-in material, is denoted by $q, \delta$ in the undersize material and $c$ in the overflow particles, based on the schematic presentation in Fig. 2, the screening efficiency can be calculated as, Magdalinović (1991):

$E=\frac{(q-c)(\delta-q)}{q(\delta-c)(100-q)} \cdot 100 \%$.

The practice have shown that the material particles whose size is smaller than three quarters of the screen's aperture easily pass through the screen, so, the largest influence on the screening efficiency impose particles whose size is close to the aperture size.

Only the factors that depend on the construction characteristics of the sieve (particularly the screen), which influence the screening efficiency, are analysed in this paper - the screen's aperture size $a$, the screen's inclination angle $\alpha$, the screen's length $L$ and the vibrations' amplitude $Y$. The vibration mode is circular. The screening efficiency, in terms of these parameters, can be written as:

$E=f(a, \alpha, L, Y)$.

The exact form of the function $f(a, \alpha, L, Y)$ does not exist; however, Wang and Tong (2011), Li et al. (2015) and Rotich (2015), who had fit it within the Mathematica ${ }^{\circledR}$ programming routine, have proposed the following expression for the screening efficiency in terms of the sieve's construction characteristics:

$E=\left(1-e^{-x(L / V)}\right) \cdot 100 \%$,

where: $x=d / a, d=a \cos \alpha-h \sin \alpha, h$ is a diameter of the wire that the screen is made of, $V$ is the rate of the raw material movement over the screen, which for the circular vibrations mode can be calculated as:

$V=Y \omega \tan ^{-1}(\omega t)$,

where $Y$ is the vibrations amplitude, $\omega$ is the angular velocity of the electro motor and $t$ is the screening time. 


\section{Results and discussion}

Influence of the aperture size $a$ on the screening efficiency of the vibration sieve is shown in Fig. 3; actually the influence of the ratio $a / d$, where $d$ represents the particle's diameter. The adopted parameters were the following: the vibrations amplitude is $Y=4 \mathrm{~mm}$, the screen's inclination angle is $\alpha=25^{\circ}$ and the screen's length is $L=2 \mathrm{~m}$.

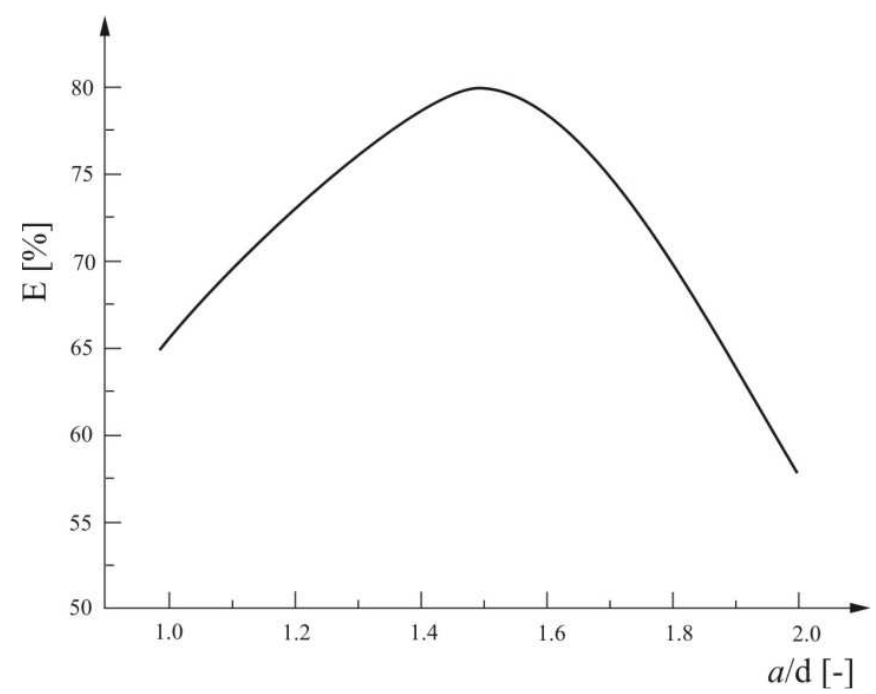

Fig. 3: Influence of the aperture size on the screening efficiency.

From Fig. 3 one can see that the screening efficiency is increasing with increase of the aperture size initially and then it starts to drop. When the aperture size small, the screening efficiency is low, considering that the aperture size is close to particle's size, thus the probability of the particle passing through the aperture is small and the large portion of undersize particles remains in the overflow material. When the aperture size is bigger, so is the screening efficiency, since the probability of the undersize particles passing through the aperture is bigger. From Fig. 3 can be seen that the maximum efficiency of close to $80 \%$ is reached for the aperture size of $1.5 \mathrm{~d}$. When the aperture size is too big, the screening efficiency is decreasing since the probability of large particles passing through the aperture is higher, so the screened product (undersize particles) is a mixture of the coarse and fine particles.

The dependence of the screening efficiency on the screen's length is shown in Fig. 4. The adopted parameters were the following: the vibrations amplitude is $Y=4 \mathrm{~mm}$, the screen's inclination angle is $\alpha=25^{\circ}$ and the aperture size $a=1.5 \mathrm{~d}$.

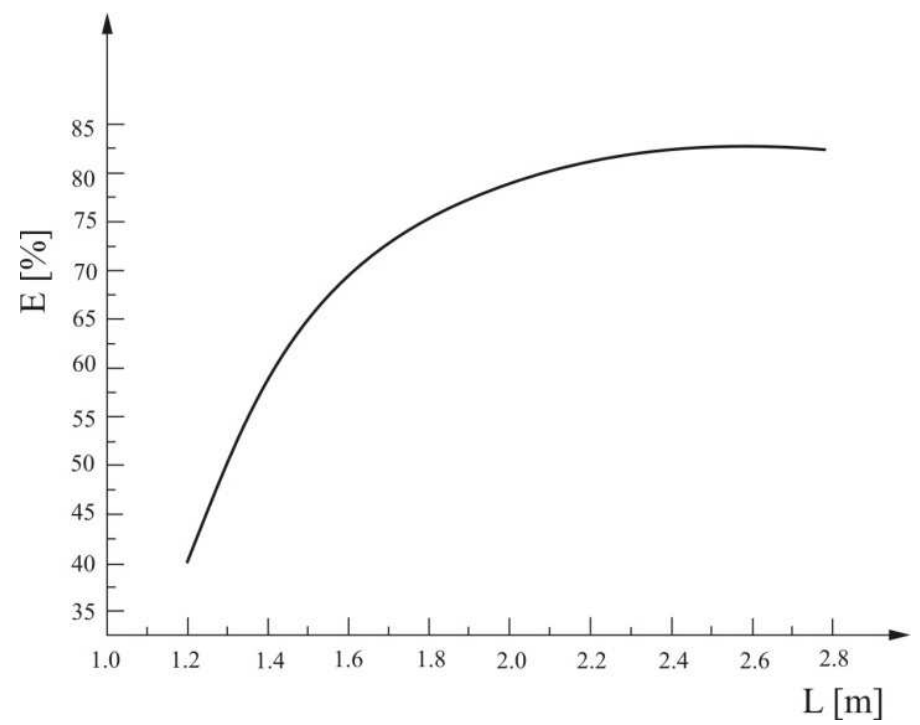

Fig. 4: Influence of the screen's length on the screening efficiency. 
From Fig. 4 can be seen that with increase of the screen's length the screening efficiency first significantly increases, then the increase becomes slower when the certain value of the screen's length is reached. The optimal screen's length is between 2.0 and $2.6 \mathrm{~m}$.

The dependence of the screening efficiency on the screen's inclination angle is shown in Fig. 5. The adopted parameters were the following: the vibrations amplitude is $Y=4 \mathrm{~mm}$, the screen's length is $2 \mathrm{~m}$ and the aperture size $a=1.5 d$.

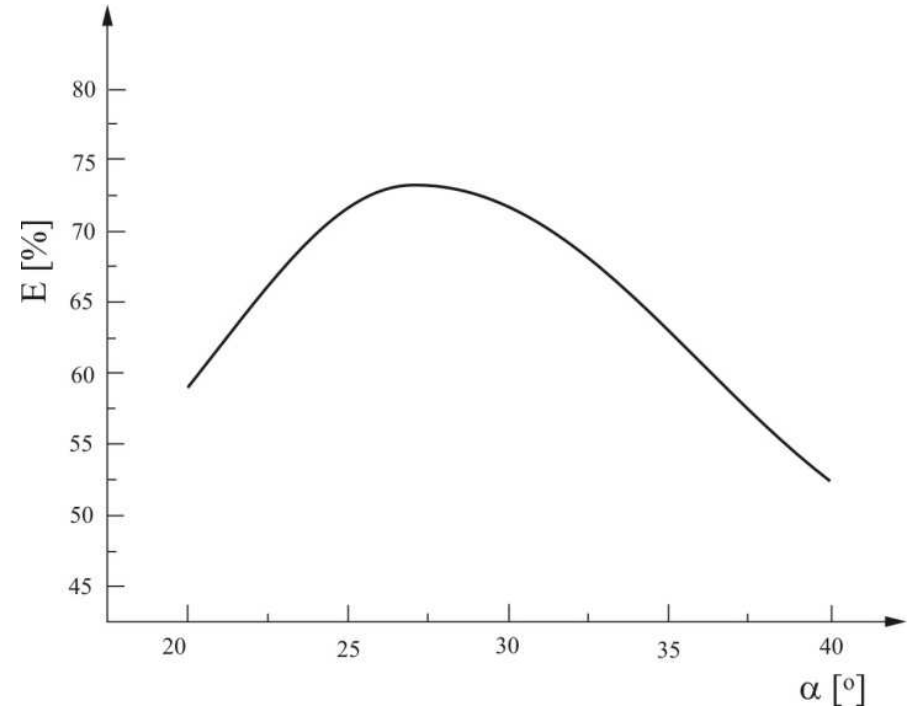

Fig. 5: Influence of the screen's inclination angle on the screening efficiency.

From Fig. 5 can be seen that the screening efficiency is increasing with increase of the screen's inclination angle until the maximum value, somewhat larger than $25^{\circ}$, is reached and then the efficiency is decreasing. When the inclination angle is increasing, the horizontal projections of the screen's aperture is decreasing, as well as the probability of particles passing through the aperture in the vertical direction, what as a consequence has decrease in quantity of particles larger than the separation size that are passing through the aperture. At the same time, passing of undersize particles is better if the speed of particles moving over the screen is increasing. Thus, with further increase of the inclination angle, the screen efficiency is decreasing due to abrupt decrease of the horizontal projection of the aperture size, the speed of particles motion is increasing and the time of particles remaining on the screen's surface is shortening.

In Fig. 6 is shown the dependence of the screening efficiency on the sieve's vibrations' amplitude. The adopted parameters were the following: the screen's length is $L=2 \mathrm{~m}$, the screen's inclination angle is $\alpha=25^{\circ}$ and the aperture size $a=1.5 d$.

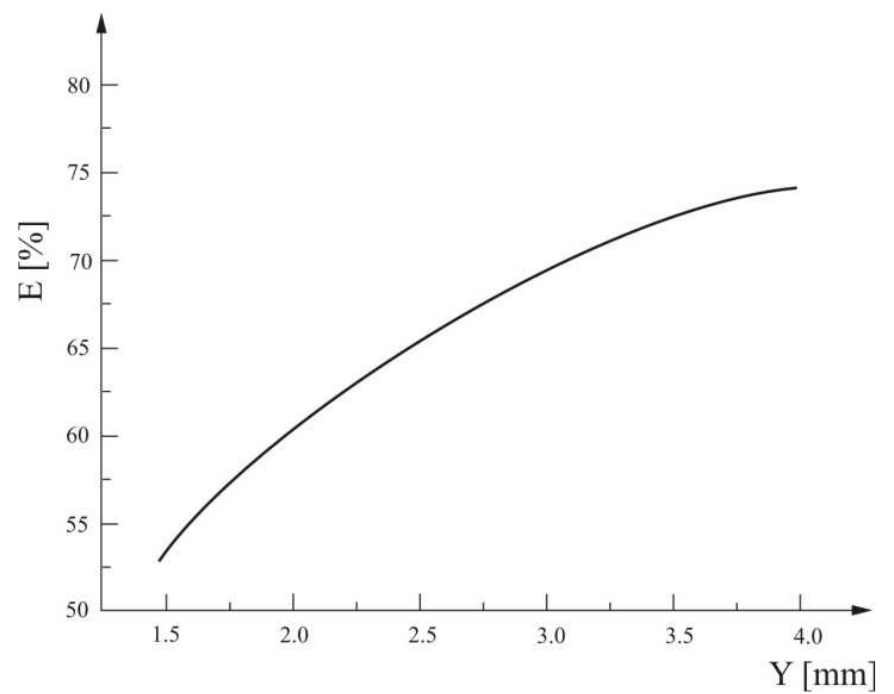

Fig. 6: Influence of the sieve's vibrations' amplitude on the screening efficiency. 
From Fig. 6 can be seen that the screening efficiency increases with increase of the vibrations amplitude. This is caused by increase of the probability of the smaller particles passing through the aperture.

\section{Conclusion}

Screening is one of the most present way of separating raw materials or products and it is widely applied in various engineering areas. The vibration sieves are the most common devices for screening. The most important characteristics of the vibration sieves is their screening efficiency.

The screening efficiency is influenced by several factors, like moisture, granulometric content, particles shape, presence of the clay materials, shape and size of the screen's aperture, screen's inclination angle number of screen's vibrations and their amplitude, whether the screening is wet or dry, what is the thickness of the material on the screen, etc. All these factors, that directly affect the probability of sieving, the screening effect and the screen's capacity, directly depend on the screening probability.

The influence of factors that depend on the construction characteristics of the device on the screening efficiency of the vibration sieves with the circular vibrations was analysed in this paper. The experimental results, obtained from literature were fitted by the programming package Mathematica ${ }^{\circledR}$ in order to obtain the mathematical expressions for dependence of the screening efficiency on the screen's aperture size, length and inclination of the screen's surface, as well as on amplitude of vibrations.

Based on results obtained by use of the proposed expressions one can conclude that the screening efficiency increases with increase of the vibrations' amplitude and length of the screening surface. On the other hand, the screening efficiency initially increases with increase of the screen's inclination angle and aperture size while it later decreases. Obtained results have confirmation in practical results from literature.

\section{Acknowledgement}

Parts of this research were supported by the Ministry of Sciences and Technology of Republic of Serbia through Grants ON174001, ON174004, TR32036 and by European regional development fund and Slovak state budget by the project "Research Centre of the University of Žilina" - ITMS 26220220183.

\section{References}

[1] LI, J. WEBB - PANDIELLA, C. - CAMPBELL, G. M.: Discrete particle motion on sieves-a numerical study using the DEM simulation, Powder Technology, Vol. 133, No. $1-3,2003$, pp. $190-202$.

[2] LIU, K. S.: Some factors affecting sieving performance and efficiency, Powder Technology, Vol. 193, No. 2, 2009, pp. $208-213$.

[3] WANG, G. - TONG, X.: Screening efficiency and screen length of a linear vibrating screen using DEM 3D simulation, Mining Science and Technology (China), Vol. 21, No. 3, 2011, pp. $451-455$.

[4] ZHAO, L. - ZHAO, Y. - LIU, C. - LI, J. - DONG, H.: Simulation of the screening process on a circularly vibrating screen using 3D-DEM, Mining Science and Technology (China), Vol. 21, No. 5, 2011, pp. $677-680$.

[5] DELANEY, G. W. - CLEARY, P. W. - HILDEN, M. - MORRISON, R. D.: Testing the validity of the spherical DEM model in simulating real granular screening processes, Chemical Engineering Science, Vol. 68, No. 1, 2012, pp. $215-226$.

[6] GROZUBINSKY, V. - SULTANOVITCH, E. - LIN, I. J.: Efficiency of solid particle screening as a function of screen aperture size, particle size, and duration of screening, International Journal of Mineral Processing, Vol. 52, No. 4, 1998, pp. $261-272$.

[7] CHEN, Y. H. - TONG, X.: Modelling screening efficiency with vibrational parameters based on DEM 3D simulation, Mining Science and Technology, Vol. 20, No. 4, 2010, pp. 615-620.

[8] JIAO, H. G. - LI, J. R. - ZHAO, Y. M.: Test and research on optimum configuration of diameter of screen aperture and incline of screen deck, Coal Preparation Technology, Vol. 35, No. 2, 2007, pp. $1-4$. 
[9] UMEHARA, S. - YAMAZAKI, T. - SUGAI, Y.: A precipitation estimation system based on support vector machine and neural network, Electronics and Communications in Japan, Vol. 89, No. 3, 2006, pp. $38-47$.

[10] FERENTINOS, K. P. - TSILIGIRIDIS, T. A.: Adaptive design optimization of wireless sensor networks using genetic algorithms, Computer Networks, Vol. 51, No. 4, 2007, pp. $1031-1051$.

[11] MAGDALINOVIĆ, N.: Fragmentation and classification of mineral raw materials, Scientific Book, Belgrade, 1991 (In Serbian).

[12] LI, Z. - TONG, X. - ZHOU, B. - WANG, X.: Modelling and parameter optimization for the design of vibrating screens, Minerals Engineering, Vol. 83, 2015, pp. $149-155$.

[13] ROTICH, N. - TUUNILA, R. - LOUHI-KULTANEN, M.: Empirical study on the effects of screen inclination and feed loading on size classification of solids by gravity, Minerals Engineering, Vol. 70, 2015, pp. $162-169$. 